\title{
Saberes populares e indígenas e suas lutas afirmativas: uma perspectiva de Educação em Direitos Humanos
}

\author{
FERNANDES, Everaldo ${ }^{1}$ \\ TAVARES, Celma ${ }^{2}$
}

\section{RESUMO}

O presente estudo objetiva estabelecer um diálogo aproximativo entre a epistemologia dos saberes populares, os saberes tradicionais indígenas e a educação em Direitos Humanos. Nesse diálogo situamos as especificidades, os nuances e organização própria de cada modo aprendente/ensinante na tentativa de perceber o que há de latente nos conteúdos e perspectivas dos Direitos Humanos nas respectivas leituras de mundo e da palavra. Nessa compreensão, estabelecemos o diálogo entre essas leituras de mundo das tradições popular e indígena (indígenas de Pernambuco), evidenciando os valores axiológicos tradicionais, e o que eles anunciam e denunciam das formalidades ideologizadas acerca da declaração dos Direitos Humanos. Nessa direção, esse diálogo contribui com as possíveis revisões dos conteúdos e formas das vivências da educação em Direitos Humanos. Para tanto, servimo-nos da abordagem das Epistemologias do Sul, sobremaneira, das contribuições de Boaventura de Sousa Santos, Paulo Freire, Ivone Gebara, Saberes do Povo Kambiwá, Susana Sacavino e Ana Maria Rodino. Concluímos que esse diálogo muito enriquece não só as discussões da educação em Direitos Humanos, mas também amplia o exercício das leituras Interculturais na perspectiva ético-política.

Saberes Populares. Saberes Indígenas. Educação em Direitos Humanos.

\section{Peoples' and Indigenous' knowledge and their affirmative fights: a perspective of Education in Human Rights}

\section{ABSTRACT}

The present study aims to establish a closer dialogue between the epistemology of the people knowledge, the traditional indigenous knowledge and the Human Rights education. In this dialogue, we set the specificities, the nuances and proper organization of each manner of learning/teaching in the attempt of realizing what is latent in the contents and perspectives of Human

\footnotetext{
${ }^{1}$ Professor Pesquisador em Educação Popular e do Pensamento de Enrique Dussel no Programa de Pós-Graduação em Educação Contemporânea (UFPE -Campus Caruaru).

${ }^{2}$ Professora Pesquisadora em Educação em Direitos Humanos no Programa de PósGraduação em Direitos Humanos (UFPE). Bolsista do Programa Nacional de Pós-Doutorado da Capes no Programa de Pós-Graduação em Educação Contemporânea.
}

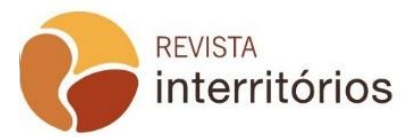


Rights in the respective reading the world and the word. In this comprehension, we establish the dialogue between these readings of world of the people's and indigenous' traditions (indigenous of Pernambuco), pointing the axiological traditional values and what they announce and denounce in the ideologized formalities about the Human Rights declaration. In this direction, this dialogue contributes with the possible contents revision and means of the experiences of education in Human Rights. Therefore, we serve of the South Epistemologies approach, especially, in the contributions of Boaventura de Sousa Santos, Paulo Freire, Ivone Gebara, the knowledge of the Kambiwá People, Susana Sacavino and Ana Maria Rodino. Concluding that this dialogue enriches not only the discussions about education in Human Rights, but also extends the exercise of intercultural readings in the ethic-political perspective.

Peoples' Knowledge. Indigenous Knowledge. Human Rights Education.

\section{INTRODUÇÃO}

Assistimos diariamente nos noticiários e presenciamos diuturnamente denúncias formais ou informais acerca dos direitos humanos vilipendiados em diferentes esferas, formas e expressões. Esses reclamos abarcam as ausências das políticas públicas às ações e reações vexatórias relativas ao racismo, à LGBTfobia, às violências domésticas, aos insultos religiosos e aos desrespeitos às diferentes culturas e formas de existir no mundo.

Nesse proscênio, entendemos que a temática dos direitos humanos e, em especial, da educação em direitos humanos tornam-se latentes e inadiáveis. Suas questões reverberam em termos de concepções, de práticas pedagógicas, de metodologias, de escolhas temáticas e de tradução cultural, pois, situamo-nos num cenário bastante plural e até mesmo intercultural.

Seguindo essa percepção e raciocínio, ensejamos desenvolver nesse presente texto os saberes populares e indígenas, especialmente, seus estruturantes epistemológicos, isto é, as principais características e organizações específicas e gerais desses respectivos saberes, como chão possibilitador de uma tradução intercultural dos direitos humanos numa perspectiva de emancipação social em diferentes contextos culturais ${ }^{3}$. Dizendo doutro modo, nosso esforço consistirá em apresentar e fazer dialogar as visões de mundo e os saberes populares e indígenas como instrumentos propiciadores de uma educação em direitos humanos numa linguagem

\footnotetext{
${ }^{3}$ Referimo-nos, especificamente, nesse texto, à população artesã do Alto do Moura - Bairro de Caruaru-PE e das populações indígenas de Pernambuco situados geograficamente no agreste e sertão do Estado.
} 
compreensiva, aproximada e instigadora para a intelecção, vivências e práticas desses referenciais axiológicos por esses mesmos sujeitos socioculturais.

Esse exercício reflexivo e pedagógico é possível numa perspectiva contra-hegemônica da construção do conhecimento (SANTOS, 2010; ARROYO, 2012), à medida que reconhecemos os sujeitos subalternizados (artesãos e indígenas, entre muitos) como construtores do conhecimento, como elaboradores de visões de mundo e como protagonistas das suas inquietações, das suas lutas e reivindicações de existirem e serem reconhecidos no sistemamundo.

Para tanto, recorremos à compreensão contra hegemônica da ciência moderna, isto é, a ecologia de saberes que, no dizer de Boaventura de Sousa Santos, significa a ciranda de reconhecimentos recíprocos dos conhecimentos, inclusive o da ciência moderna, ou seja, a presença da horizontalidade dos conhecimentos produzidos pela humanidade em que todos os saberes têm validação, organização própria, legitimidade e também limites. Isto porque "o objetivo da ecologia de saberes é ampliar a legitimidade intelectual e cultural das lutas pela dignidade humana" (SANTOS, 2014, p. 107). Desse modo, tem assentimento o exercício epistemológico de que todo conhecimento goza de incompletude, de que as realidades constituintes da vida são múltiplas e complexas que não se deixam confinar por um olhar analítico-explicativo, tampouco compreensivo unilateral e dominante que caracterizam a monocultura tão combatida pelas epistemologias do Sul (MALDONADOTORRES, 2010; IVONE GEBARA, 2017; ENRIQUE DUSSEL, 1996). Numa palavra, para Santos, conhecimento é interconhecimento e não a ciência moderna advogar para si o status de um saber prevalecente, do pensamento único e iconoclasta dos demais.

Seguindo esse propósito e itinerário reflexivo-pedagógicos, faremos o presente percurso: 1) apresentaremos a epistemologia dos saberes populares; 2) Visões de Mundo e Saberes Tradicionais dos povos indígenas de Pernambuco e, por fim, a interface com a educação em direitos humanos: possíveis traduções e reinvenções pedagógicas nesses diferentes contextos culturais.

1 Epistemologia dos Saberes Populares: contribuições dos/as artesãos/ãs do agreste pernambucano

Ao trazer essa questão à baila, queremos esclarecer que não se trata de uma compreensão de totalidade, isto é, de um retrato descritivo e caracterizador universal da produção de conhecimento dos saberes populares. 
A nossa intelecção aqui compartida trata-se de resultados de uma pesquisa em educação com os/as artesãos/ãs do Alto do Moura ${ }^{4}$, especialmente, com sujeitos sociais que são referências socioculturais nesse bairro artesão de Caruaru-PE sem a passagem pelos bancos escolares. Nosso olhar compreensivo desenvolveu-se, sobremaneira, com os/as colaboradores/as da pesquisa que teceram processos autônomos e ousados das suas múltiplas aprendizagens sem a mediação da escola, consoante as estratégias de aquisição, apropriação, circulação e validação dos seus conhecimentos nos espaços da comunidade artesã, cujos resultantes materializaram-se nos ofícios da arte em barro, na leitura e na escrita e nos espaços associativos e comunitários desse bairro artesão.

Portanto, não se trata de uma reposição do pensamento único ou de uma epistemologia unívoca dos saberes populares, mas de uma interpretação aproximativa da elaboração desses saberes que têm características próprias e suficientes para que possamos preconizar que há uma sistematização específica de inteligir, de elaborar, de circular, de referendar e validar os conhecimentos desses sujeitos sociais agrestinos.

Antes de tratarmos, diretamente, da epistemologia dos saberes populares, queremos chamar a atenção de que verificamos que são processos aprendentes e ensinantes e não de estratégias dos artesãos em seus modos de aprendizagem sem necessariamente passar pelos bancos escolares. Entendemos por processos aprendentes todo 0 arcabouço contextual, mobilizador, dinâmico e criativo que abrange o modus vivendi e as iniciativas ousadas desses sujeitos no esforço pessoal de revisitar suas situações adversas e enfrentá-las mediante os instrumentos da leitura, da escrita e fazimento artístico no barro. Se situássemos tão-somente o conjunto de estratégias buscadas e exercitadas pontualmente pelos/as artesãos/ãs, restringiria, sem dúvida, o conjunto de amálgamas constituintes, criativos e possibilitadores das leituras de mundo que esses sujeitos têm produzido diuturnamente.

Em destaque da vivência desses processos aprendentes-ensinantes desses sujeitos artesãos, que resultou no entendimento da epistemologia dos saberes populares, temos:

$\checkmark$ Os Sonhos Mobilizadores: Perante cada dificuldade enfrentada desde a infância por esses sujeitos (empobrecimento acentuado, ausência da

\footnotetext{
${ }^{4}$ Este bairro destaca-se pela sua pujança no artesanato em barro e também em outras tradições culturais, como a mazurca, o reisado e o pastoril Perna de Pau. Em torno de mais de novecentas pessoas produzem essas artes como meio de sobrevivência material e de resistência simbólica. Nesse espaço-tempo, lemos os saberes populares como resultado de uma pesquisa que culminou numa tese de doutoramento em 2011, defendida no Centro de Educação na Universidade Federal de Pernambuco.
} 
escola, não contatos com livros, fome e subalternizações em relação às pessoas da cidade etc.), continuamente, buscaram modos e ferramentas de superação. Os seus sonhos de uma vida melhor, com as condições básicas satisfeitas, bem como de dignidade, serviram-lhe de base construtiva de buscas e de superação. Para tanto, utilizaram algumas ferramentas da observação, da repetição, da correção e da criação (SILVA, 2011, p. 209). Tanto para a aquisição da leitura, da escrita e das habilidades do manuseio artístico do barro, esse caminho (método) foi seguido ora de modo linear, ora em saltos, quando da observação já se alcançou a criatividade, mediante as histórias distintas de cada um/a.

Desse modo, os sonhos de uma vida digna e de reconhecimento de existir e de ser no mundo mobilizaram esses sujeitos em suas buscas aprendentes e cidadãs tanto na arte como na leitura do mundo e da palavra. Noções tão caras ao pernambucano Paulo Freire.

$\checkmark$ O Cruzamento Múltiplo e Criativo: nessa característica dos saberes populares, evidenciamos as interinfluências que inspiram e cimentam as construções dos saberes populares, a saber, os conselhos dos anciãos/ãs, as práticas religiosas, as experiências imediatas extraídas do cotidiano, as histórias de vida, os cordelistas, os turistas e visitantes do bairro artesão. Essas múltiplas influências se imbrincam, desenham voluntário e involuntariamente o imaginário social dessas pessoas que formam continuamente suas visões de mundo, bem como revisitam os seus papéis sociais que a dinâmica socioeconômica impõe. Nessas múltiplas influências, esses artistas populares demarcam espaços, recriam suas interpretações e resistem às contínuas investidas dos atravessadores nos negócios do artesanato, das políticas verticalistas do poder municipal e da luta política pelo reconhecimento da profissão de artesão pelo ministério do trabalho, cuja empreitada ainda se mostra distante de efetivação.

$\checkmark$ O Lócus Aprendente: se a escola não se constitui o lugar das suas aprendizagens, onde elaboram as suas leituras de mundo e das letras? - No chão do cotidiano (MICHEL DE CERTEAU, 2004), as ruas, as conversas informais, as reuniões da Associação dos Artesãos, os encontros nas igrejas e a feira livre tornam-se espaços-tempo de trocas de saberes, de confrontos de ideias, de lutas políticas e de buscas de afirmação dos sujeitos. Ademias, o interior das casas também tem sido outro espaço de novas aprendizagens, quando e onde a mesa das refeições - lugar sagrado da comida e das conversas familiares, as histórias de vida têm assento, as últimas notícias do dia são repassadas e os confrontos intergeracionais adquirem força e materialidade. Nesses 
espaços em que o cotidiano é forjado e retroalimentado, essas pessoas artesãs revisitam suas percepções, avaliam suas práticas de algum modo, exercitam as forças e ganham energias para a batalha diária pela sobrevivência material, pelos significados de vida e pela afirmação cidadã.

$\checkmark$ Saberes tecidos pela autoformação e pela confirmação social: Por autoformação entendemos os processos que individual e coletivamente vamos elaborando, sobremaneira, quando as histórias de vida têm um destaque nas construções aprendentes e cuja dinâmica tem respingos multifacetados. Ou seja, são as formas e modos de aprendizagem em que os sujeitos tecem com certa autonomia a interrelação de vida e conhecimento, de influências externas e ressignificações internadas, cujo entrelaçamento resulta num saber empoderador, emancipador. No caso dos sujeitos artesãos do Alto do Moura, enxergamos que houve, simultaneamente, uma tríplice aprendizagem: nas letras, na modelagem do barro e na liderança social. Com essa performance sociocultural esses sujeitos gozam de certo destaque na vida da comunidade, na qual são reconhecidos como pessoas dotadas de sabedoria que engendra os saberes da prática, das experiências de vida e as capacidades de resistência num tom afirmativo da cidadania artesã.

Todavia, esses saberes elaborados não dispensam as avaliações, o assentimento social à medida que ao fazer uma peça os pareceres dos turistas e os comentários dos mais experientes são dignos de registro ora positivamente, ora reparando e sugerindo algumas melhorias estéticas. Do mesmo modo, ao declamar uma poesia de improviso ou produzi-la em versos escritos, o reconhecimento social também se faz valer através dos aplausos ou dos recadinhos de como melhorar a rima entre uma e outra estrofe.

Nessas idas e vindas, nas repetições e criações, esses saberes vão se erigindo, se afirmando, tendo destaque os processos de autonomia desses sujeitos sociais, cuja autoformação está se alicerçando no cotidiano, nos espaços sociais e nas lutas afirmativas dos saberes em busca de cidadania todo tempo.

Nesse itinerário compreensivo, afirmamos que a epistemologia dos saberes populares é construída numa perspectiva transdisciplinar, reunindo, dialogicamente, as condições reais de vida e os sonhos mobilizadores, a subjetividade e a objetividade, as intuições e as estratégias de superação, ao mesmo tempo, que o material e o espiritual, as resistências e a criatividade, 0 imaginário social e as brechas de afirmação de ser sujeito de valor, de reconhecimento social, mediante a aquisição das letras, do aperfeiçoamento 
estético do barro e das lutas políticas na Associação dos Artesãos/as local e no enfrentamento dos compradores e dos representantes da Fundação de Cultura de Caruaru.

Aferimos a presença da ecologia de saberes, conforme trouxemos anteriormente, pois, vários saberes são postos em relação e a construção intercultural e interepistêmica caminham em diálogo com tensões, mas como ensaios de novas buscas de contracenar as diferentes identidades, os distintos saberes e as várias formas e modalidades de se erigir conhecimentos válidos. Caminho este, significativo, para se colocar os teores e discussões dos Direitos Humanos, cuja pauta pode traduzir os valores éticos e as referências culturais como campos de tradução da pretensa carta de acordos gerais da humanidade. Nesse caminho, acreditamos ser um facilitador para as releituras regionais e locais dos Direitos Humanos à medida que esses referenciais valorativos perfazem as culturas subalternizadas, caracterizadas pela leitura elitista como saberes que portam conhecimentos inválidos, ingênuos e anacrônicos. Desse modo, a Declaração dos Direitos Humanos passa por uma rediscussão popular, segundo seu universo cultural e vocabular; assim como essa mesma declaração tem a possibilidade de se revestir das peculiaridades socioculturais, especialmente, a partir dos sujeitos invisibilizados.

\section{Visões de Mundo e Saberes Tradicionais dos Povos Indígenas de Pernambuco}

Nesse segundo momento da nossa reflexão, iremos nos debruçar sobre as cosmovisões indígenas e, focadamente, a tessitura dos seus saberes que reúnem elementos de cosmogonias diversas, marcadas pela presença do sagrado, pela ancestralidade, pela oralidade e pela relação de respeito e apreço à natureza, à terra-mãe, sentidas e interpretadas como prenhes de sabedoria e dignas de reverência.

Referimo-nos, especificamente, aos povos indígenas de Pernambuco, cuja população consta, atualmente, com mais de quarenta e sete mil pessoas, situadas no agreste e no sertão do Estado. Esses povos distribuídos em 12 etnias são eles: Atikum, Kambiwá, Kapinawá, Pankaiuká, Pankará, Pankararu, Pipipã, Truká, Xukuru, Entre Serras, Tuxá e Fulni-ô. Este último é o único povo que ainda conserva o seu idioma de origem: o Yaathê. Portanto, mantém-se como uma população bilíngue e as demais etnias falam somente a língua portuguesa e alguns vocábulos dos seus respectivos idiomas de origem ${ }^{5}$.

\footnotetext{
${ }^{5} \mathrm{~A}$ aproximação com essas populações indígenas de Pernambuco deveu-se à vivência do Pibid-Diversidade, isto é, o Programa Institucional de Bolsas de Iniciação à Docência vivido 
Tendo presente todo esse horizonte contextual e linguístico dessas populações, a educação escolar indígena tem se consolidado, sobretudo em termos de processos de lutas políticas no sentido de retomadas no só dos territórios como das escolas nas aldeias que até a pouco estavam em sua maioria sob a égide político-pedagógica do Estado ou do Município. Ademais, a retomada da política dos direitos de uma educação específica, diferenciada, comunitária e intercultural em que a relação escola e comunidade e os saberes escolares e tradicionais façam-se valer e respeitar num olhar horizontal.

Para tanto, essas lutas e retomadas têm-se dado mediante a busca de efetivação de concepções e práticas outras, bem como modos outros de se fazer educação básica em que haja uma repaginação da leitura da história e das condições reais de vida dos subalternizados no sentido de autocompreensões e de posturas afirmativas em relação à memória coletiva (diferenciada das narrativas ditas oficiais presentes na maioria dos livros didáticos), às identidades indígenas, aos direitos à educação diferenciada e à autonomia de elaboração de currículos específicos que contemplem os saberes tradicionais e a presença das lideranças nas salas de aula. Outrossim, o reconhecimento da montagem própria dos calendários indígenas, cujas datas são significativas no imaginário social indígena.

Essa perspectiva educacional e identitária é possível quando, efetivamente, se "reconhecer que esses povos têm outras pedagogias produtoras de saberes, de modos de pensar, de se libertar e humanizar desestabilizaria a própria autoidentidade da pedagogia hegemônica" (ARROYO, 2012, p. 30). Trata-se de um processo de política identitária denso, engenhoso, beligerante e fronteiriço, cujo protagonismo em nosso Estado se deve à COPIPE (Cooperativa dos Professores Indígenas de Pernambuco) que, incansavelmente, vem há algum tempo pleitear as políticas públicas de uma educação diferenciada para os povos indígenas que abrangem a autonomia dos currículos, a valorização profissional (concursos públicos), a gestão escolar participativa com ênfase comunitária e o reconhecimento da Licenciatura Intercultural Indígena na UFPE, tornando-se um espaço garantidor da formação inicial e continuada dos docentes indígenas das nossas regiões agreste e sertão.

Descrito esse proscênio contextual e político dos indígenas de Pernambuco, passemos, então, aos elementos que caracterizam ao mesmo tempo as visões de mundo e os saberes tradicionais que se imbrincam mutuamente.

entre 2014-2018, celebrado entre a Universidade Federal de Pernambuco (UFPE) e a CAPES/SECADI que visa ampliar a formação dos/as professores/as indígenas em termos das suas práticas pedagógicas na educação básica, com os marcos de uma educação específica e diferenciada. 
$\checkmark$ A Ancestralidade. Esse aspecto é demais precioso para a identidade indígena, para o fortalecimento das lutas do povo. O pertencimento aos antepassados é indispensável, pois, se trata da presença e força dos ancestrais, dos encantados, cuja potência guerreira caminha latentemente na vida dos indivíduos e da coletividade. $O$ entender-se hoje em termos identitários emerge das ligações com os antepassados. Significa que eu sou índio a partir de um passado longevo que enraíza os sujeitos indígenas entre si e com o seu futuro confrontativo e exigente mediante às vicissitudes histórico-culturais.

O Pajé tem essa função específica, conforme os Kapinawá, de manter a união do povo, uma vez que ele detém “... os saberes espirituais e conhecer a história, responsável de passar adiante a cultura, as histórias, os rituais e as tradições" (KAPINAWÁ CEEIK, 2016, p. 36).

A ancestralidade é a raiz e a âncora de sustentação do vigor identitário de um povo, pois é o que assegura a tradição e a continuidade das crenças, das lembranças coletivas, dos valores e educação herdados, bem como das forças embutidas nas lutas diuturnas de afirmação das suas existências socioculturais específicas.

$\checkmark$ A Coletividade. Pela ancestralidade, o fio condutor da história coletiva mantém-se vivo e possibilitador de confrontos interculturais de forma aberta e sem maiores riscos de obliterar as diferenças culturais. Esse fio ancestral interliga os encantados (os espíritos dos heróis e heroínas de cada povo) aos atuais membros das aldeias de uma população indígena. Isto configura-se não somente enquanto presença saudosa e enlutada, mas, sobretudo, como presença ativa, energizante de vida de um povo, unificando-o, reunindo-o em torno de uma luta que enceta esforços coletivos, criativos e resistentes. Pois, os encantados também são consultados para dirimir os rumos, as escolhas difíceis condizentes à vida coletiva indígena.

Desse modo, entendemos e situamos o valor da coletividade para as culturas indígenas, pois, o todo está interligado tanto à presença e memória aparentemente distantes e, ao mesmo tempo, próximas, consistentes, com poder de interferência na organização da vida e nas lutas afirmativas que adquirem substrato de sobrevivências material e simbólica.

Não queremos preconizar que não há sinais fortes de ingerência da cultura do não-índio no imaginário atual das aldeias, caracterizada pelo acento nos indivíduos e na competitividade, no entanto, a dimensão do coletivo é bastante presente e fortalecedora na vida de cada povo. 
$\checkmark$ A Relação com o Sagrado. Esse viés é estruturante como herança ancestral, como elemento aglutinador de cada povo e como expressão das suas subjetividades coletivas. A dimensão religiosa tem esse poder catalisador tanto da renovação das forças subjetivas dos indivíduos, como da função de congregar pessoas, reuni-las em torno de interesses comuns, unificadores, miméticos (de anamnese: memória ativa e de renovação de ideais) e de subjetivação de valores coletivos.

Entre os povos indígenas do nordeste, a presença do terreiro (espaço sagrado, em geral, circunferencial, no qual os rituais são desenvolvidos, são celebrados) é notado e indispensável, pois, trata-se do espaço religioso indígena por cima da terra sagrada que enraíza e reúne os povos das aldeias.

Nas aldeias acontecem as festas religiosas dentro de um calendário que contemplam os santos católicos e as memórias nativas dos povos originários. Isto se registra, com os Kapinawá, quando dizem que "as festas e as novenas sempre foram tradição desde os nossos antepassados e nossas antepassadas" (Ibidem, 2016, p. 46). Contudo, o papel do Pajé não é ofuscado. Sua referência como liderança religiosa se mantém, cuidando das pajelanças (cura de doenças), dos aconselhamentos, de revelar os segredos da natureza e de puxar o Toré (dança circular que invoca os encantos de luz e reforça a união do povo). Em sendo assim, o Pajé tem o papel fundamental de zelar pela união do povo, pela manutenção da ciência indígena e de evocar a indissociabilidade da ancestralidade como raiz da coletividade.

$\checkmark$ A Relação com a Terra, com a Natureza. Como extensão da compreensão da presença sagrada, a terra, as serras, as matas, os rios e tudo o que constitui a natureza é considerada e tratada como habitação dos ancestrais, não somente porque muitos estão sepultados nesses territórios, mas também por portar sabedoria, a ciência da natureza em termos de produção de remédios e de ser porta reveladora dos destinos do povo. Segundo o povo Kapinawá "nas matas estão as plantas medicinais e sagradas, como a jurema, que é a base dos nossos rituais. Por isso é tão importante para nós" (Ibidem, 2016, p. 72).

Entendemos desse modo, que há uma simbiose simbólica em que a presença dos ancestrais, a sensibilidade do coletivo, os rituais e as vivências cosmogônicas (espacialidade/tempo vividos como centralidade da vida e do cosmos, como referências de aconchego e de acolhida no mundo: metáfora do ninho humano) entrelaçam-se formando uma tessitura de fontes identitárias, de arroubos espirituais, dos saberes tradicionais e, ao mesmo tempo, de força política decolonial e afirmativa das suas histórias e existências.

Para isso, a organização do povo e os destinos coletivos são liderados pelo cacique (liderança política), pelo pajé (liderança religiosa e da ciência da 
natureza) e pelo conselho dos anciãos que têm papéis preponderantes em termos da condução da vida coletiva, do enfrentamento das suas lutas afirmativas, da vivência dos rituais sagrados e das situações decisivas na política, na educação, na saúde etc.

A natureza tem papel importante nas escolhas das lideranças, bem como nos episódios decisivos da vida do povo, quando nessas situações os mais velhos adentram as matas e consultam os encantos de luz, buscando discernimento e coragem para dirimir questões relativas aos destinos da coletividade. Esses rituais são reservados aos mais velhos e não é permitido o acesso de outros membros da própria comunidade, tampouco de pessoas nãoíndias.

Por fim, as visões de mundo desses sujeitos sociais são marcadamente revestidas pelo ciclo lunar, pelos segredos da natureza, pelo ritmo de vida do campo, pelos saberes oriundos da terra e da natureza, derivando tudo isto numa compreensão singular da relação e trato com as questões socioambientais, com os saberes que provém da lógica urbanocêntrica, da medicina alopática, das tradições cristãs e das políticas governamentais em seus múltiplos espectros. Com esse arcabouço compreensivo, ora a ecologia de saberes entra em cena; ora os conflitos de territórios e saberes são acirrados a depender dos interesses em voga, dos atores em ação e das situações-contextos que a pauta de luta se dê e se manifeste.

No fim dessa sessão, compreendemos que os saberes populares e indígenas se aproximam, são correlatos, salvaguardando as devidas especificidades e que ambos possibilitam uma aproximação dialógica com a educação em direitos humanos, pois, tanto estes propõem-se ter presente uma visão ampliada acerca da ausência dos reconhecimentos da existência dos sujeitos sociais, ao mesmo tempo que também essa educação se permite interpelar e traduzir suas intencionalidades levando em conta saberes outros, afinal, como nos advoga Arroyo: " [...] as teorias e pedagogias socioeducativas terão que repensar as formas como têm sido pensados os diversos e os diferentes em classe, raça, etnia, gênero, campo, periferia" (Ibidem, 2012, p. 59).

\section{Saberes Populares e Tradicionais e suas Interfaces com a Educação em Direitos Humanos}


A compreensão acerca das aproximações existentes entre saberes populares e indígenas e educação em direitos humanos $(E D H)^{6}$ encontra ressonância nas diretrizes que norteiam estes saberes e suas práticas.

Seguindo a perspectiva contra-hegemônica da construção do conhecimento encontramos na pedagogia crítica a base de fundamentação da educação em direitos humanos. De acordo com Magendzo (2008, p. 118) a pedagogia crítica "examina como a estrutura educativa e o currículo interagem para dar forma ao conhecimento", enquanto a pedagogia em direitos humanos "se preocupa com a forma com a qual a estrutura educativa e o currículo conseguem moldar o 'sujeito de direito"'.

Dessa forma, a prática pedagógica em direitos humanos busca contribuir ao empoderamento individual e coletivo, fomentando as capacidades para o desencadeamento de processos de democratização e transformação.(SACAVINO, 2000, p. 47).

Nesta direção a interface entre a educação em direitos humanos e os saberes populares e indígenas aponta a um trabalho permeado pela perspectiva de processo; pelo reconhecimento da existência de diferentes conhecimentos; pelo estímulo à dialogicidade, autonomia e criticidade; pela exigibilidade de políticas e direitos. Tudo isso respeitando o protagonismo dos sujeitos envolvidos (que estão se formando enquanto sujeito de direito); articulando conhecimentos e o cotidiano de suas práticas sociais; e estimulando a interlocução com o poder público.

Para isso um elemento fundamental é a conjugação dos princípios e das metodologias adotadas. Da mesma forma que a epistemologia dos saberes populares e das visões de mundo e os saberes tradicionais, a educação em direitos humanos abarca uma ética que considera a coletividade, os sonhos enquanto mobilizadores, as histórias dos sujeitos que lutaram contra as violações de direitos humanos, e a multiplicidade dos saberes contextualizados igualmente relevantes e legítimos.

Em relação aos seus princípios, é preciso inicialmente assinalar a EDH é em essência uma educação política porque forma pessoas comprometidas com a transformação da sociedade, é também uma educação ético-valórica e contextualizada, que deve avançar de uma concepção normativo-jurídica para uma posição pedagógica holística e integral, e contribuir para consolidar a democracia e a paz e construir o sujeito de direito (MAGENDZO, 2009).

\footnotetext{
${ }^{6}$ No Brasil, o Plano Nacional de Educação em Direitos Humanos define a educação em direitos humanos como um processo sistemático e multidimensional que orienta a formação do sujeito de direito e articulando diversas dimensões, congregando o campo do conhecimento, o campo das atitudes e valores e o campo da ação (BRASIL, 2006). 
Além disso, para nortear esse trabalho, e considerando que a EDH busca atuar na formação integral da pessoa, desenvolvendo sua condição de sujeito de direito, Magendzo (2006, pp. 67-70) defende a aplicação dos seguintes princípios, que se relacionam as implicações práticas indicadas:

Quadro 1 - Princípios e práticas da formação integral

\begin{tabular}{|l|l|}
\hline \multicolumn{1}{|c|}{ PRINCÍPIOS } & \multicolumn{1}{|c|}{ PRÁTICAS } \\
\hline Integração & $\begin{array}{l}\text { Os temas e conteúdos de direitos humanos fazem parte integral } \\
\text { dos conteúdos e atividades do currículo e dos programas de } \\
\text { estudo7. }\end{array}$ \\
\hline Recorrência & $\begin{array}{l}\text { O aprendizado em direitos humanos é obtido na medida em } \\
\text { que é praticado uma e outra vez em circunstâncias diferentes e } \\
\text { variadas. }\end{array}$ \\
\hline Coerência & $\begin{array}{l}\text { A coerência entre o que se diz e o que se faz é parte } \\
\text { importante neste ambiente, pois o êxito do aprendizado é } \\
\text { reforçado quando se cria um ambiente propício para seu } \\
\text { desenvolvimento. }\end{array}$ \\
\hline Vida cotidiana & $\begin{array}{l}\text { Como a EDH está estreitamente vinculada com a } \\
\text { multiplicidade de situações da vida cotidiana, é necessário que } \\
\text { os(as) educadores(as) resgatem essas situações e momentos } \\
\text { nos quais os direitos humanos estão em jogo. }\end{array}$ \\
\hline $\begin{array}{l}\text { Construção coletiva } \\
\text { do conhecimento }\end{array}$ & $\begin{array}{l}\text { É importante que as pessoas analisem grupalmente a } \\
\text { informação e vivência sobre direitos humanos, deixando de ser } \\
\text { receptores(as) passivos(as) para tornar-se produtores(as) de } \\
\text { conhecimento }\end{array}$ \\
\hline Apropriação & $\begin{array}{l}\text { A pessoa se apropria do discurso recebido e o recria, ou seja, } \\
\text { reelabora as várias mensagens e as traduz num discurso } \\
\text { próprio, do qual toma plena consciência e que passa a orientar } \\
\text { as atuações da sua vida. }\end{array}$ \\
\hline
\end{tabular}

Fonte: Material produzido pelos autores.

\footnotetext{
${ }^{7}$ O princípio da integração citado por Magendzo para o contexto escolar é igualmente necessário em qualquer ambiente educativo. 
A esfera metodológica do processo de EDH, por sua vez, precisa trabalhar simultaneamente três eixos: os conhecimentos; os valores e atitudes; e as capacidades para atuar (RODINO, 2003, p. 5). Do contrário corre-se o risco de se utilizar estratégias relacionadas ao ensino frontal, baseado no modelo expositivo, com transmissão do conhecimento (em lugar de sua produção coletiva) e pouco (ou nenhum) diálogo. O que não corresponde aos objetivos da EDH e tampouco contribui à mudança de comportamentos e mentalidades que esta busca promover (CANDAU, 2008).

Além disso, é indispensável definir o que se pretende estabelecer com o processo de EDH, como também assegurar que os conhecimentos e a realidade concreta não sejam abordados de forma fragmentada ou restrita. A EDH deve permear todos os conteúdos, as atitudes, os comportamentos e as práticas pedagógicas nos espaços educativos, desenvolvendo um processo de ação-reflexão-ação, conforme proposto na pedagogia freireana.

Assim, o diálogo que pode ser aberto entre a educação em direitos humanos, os saberes populares e os saberes tradicionais reforça a ideia de que uma educação que busque fomentar a autonomia, a liberdade, a criticidade e a ação tem de se apoiar em uma prática pedagógica democrática, humanizadora e condizente com a defesa dos direitos de todas as pessoas, respeitando, logicamente, as peculiaridades de cada processo.

Nesta intersecção outro ponto que as une é a defesa dos direitos e a transformação da realidade. Os direitos humanos, neste contexto, apresentamse como elemento importante para as mudanças sociais. Contudo, é necessário superar a compreensão oficialista desses direitos para que sua luta congregue as especificidades dos sujeitos sociais, como por exemplo, a ancestralidade, a coletividade, a relação com o sagrado e a relação com a terra, com a natureza que caracterizam os povos indígenas. Desde a perspectiva crítica dos direitos humanos, estes são compreendidos como "processos institucionais e sociais que possibilitem a abertura e consolidação de espaços de luta pela dignidade" (HERRERA FLORES, 2008, p. 13). Ou seja, a concepção não se centra nos direitos como algo a priori, mas sim como "resultados, sempre provisórios, das lutas sociais por dignidade". Por isso mesmo, faz-se necessário superar o que Sanchéz Rubio (2011, p. 51-52) chama de 'situação anestésica' em que nos encontramos em relação a estes direitos, decorrente da "concepção jurídico-positivista, estatista e formalista dos direitos humanos", que nos situa em uma concepção pós-violatória dos direitos humanos, e caminhar em direção à dimensão pré-violatória destes direitos, que exige uma atuação conjunta para que a violação não ocorra e um processo educativo constante.

Os saberes populares e tradicionais, portanto, aportam à educação em direitos humanos, e vice-versa, as condições para esta atuação conjunta, com 
a contribuição específica de cada um e o que de comum se identifica entre eles; tendo a humanização como ponto de partida e de chegada.

Por fim, essas três perspectivas possibilitam trabalhar duas dimensões essenciais: a emancipadora e a transformadora. Através delas, é possível sensibilizar, indignar-se, atuar e comprometer-se. Algo que até o presente momento tem sido o caminho seguido por todas elas.

Desde este olhar, sempre situado e sem a pretensão de totalidade, conforme exposto anteriormente, é que compreendemos as interfaces entre saberes populares e tradicionais e a EDH a fim de possibilitar uma tradução intercultural dos direitos humanos numa perspectiva de emancipação social em diferentes contextos culturais.

\section{REFERÊNCIAS}

ARROYO, Miguel. Outros Sujeitos, Outras Pedagogias. Petrópolis: Vozes, 2012.

BITTAR, Eduardo (org.). Educação e Metodologia para os Direitos Humanos. São Paulo, Quartier Latin, 2008, p. 285-298.

CANDAU, Vera. Educação em direitos humanos: questões pedagógicas. In: BITTAR, Eduardo (org.). Educação e Metodologia para os Direitos Humanos. São Paulo, Quartier Latin, 2008, p. 285-298.

CERTEAU, Michel de. A Invenção do Cotidiano 1 - Artes de fazer. Tradução de Ephraim Ferreira Alves. 10. Ed. Petrópolis: Vozes, 2004.

DUSSEL, Enrique. Filosofía de la Liberación. Bogotá: Editorial Nueva America, 1996.

GEBARA. Ivone. Filosofia Feminista: uma brevíssima introdução. São Paulo:

Edições Terceira Via, 2017.

HERRERA FLORES, Joaquín. La reinvención de los derechos humanos. Sevilla, Atrapasueños, 2008.

MAGENDZO, Abraham. Derechos humanos: un desafío para los docentes de hoy. Santiago: LOM Ediciones, 2006.

La escuela y los derechos humanos. México - DF, Cal y Arena, 2008.

Pensamiento e ideas-fuerza de la educación en derechos humanos en Iberoamérica. Santiago, Chile, OIE/Orealc/Unesco, 2009.

MALDONADO-TORRES, Nelson. A Topologia do Ser e a Geopolítica do Conhecimento. Modernidade, império e colonialidade. In: MENESES, Maria Paula e SANTOS, Boaventura de Sousa. Epistemologias do Sul. São Paulo: Cortez, 2010, p. 396-443. 
PROFESSORAS E PROFESSORES KAPINAWÁ. Kapinawá - Território, Memórias e Saberes. CEEIK. Funcultura: Recife, PE, 2016.

RODINO, Ana María. Educación para la vida en democracia: contenidos y orientaciones metodológicas. San José. Instituto Interamericano de Derechos Humanos, 2003.

SACAVINO, Susana. Educação em Direitos Humanos e Democracia. In: CANDAU, Vera e SACAVINO, Susana. Educar em Direitos Humanos. Rio de Janeiro, D\&P Editora, 2000, pp. 36-48.

SÁNCHEZ RUBIO, David. Democracia y derechos humanos: una perspectiva crítica. En: Proyecto Socialización Digital del Conocimiento. Documentos de Estudio, n.1, Heredia, Costa Rica, IDELA/UNA, 2011, p. 7-61.

SANTOS, Boaventura de Sousa. A Gramática do Tempo - para uma nova cultura política. (Coleção: Para um novo senso comum; Vol 4), 3. Ed. São Paulo: Cortez, 2010.

Se Deus Fosse Um Ativista dos Direitos Humanos. São Paulo: Cortez, 2014.

SILVA, Everaldo Fernandes da. Processos Aprendentes e Ensinantes dos/as Aresãos/ãs do Alto do Moura: tesitura de vida e formação. Recife: Universidade Federal de Pernambuco, Centro de Educação. Tese de Doutoramento, 2011. 